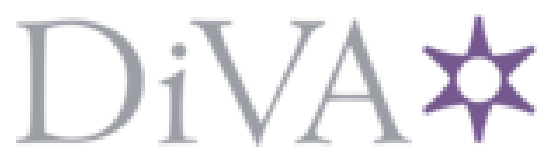

http://www.diva-portal.org

This is the published version of a paper presented at 14th International Symposium on Computer Music Multidisciplinary Research.

Citation for the original published paper:

Gulz, T., Holzapfel, A., Friberg, A. (2019)

Developing a Method for Identifying Improvisation Strategies in Jazz Duos

In: M. Aramaki, O. Derrien, R. Kronland-Martinet, S. Ystad (ed.), Proc. of the 14th

International Symposium on CMMR, Marseille, France, 2019 (pp. 482-489).

N.B. When citing this work, cite the original published paper.

Permanent link to this version:

http://urn.kb.se/resolve?urn=urn:nbn:se:kth:diva-263053 


\title{
Developing a Method for Identifying Improvisation Strategies in Jazz Duos.
}

\author{
Torbjörn Gulz ${ }^{1}$, Andre Holzapfel ${ }^{2}$, and Anders Friberg ${ }^{2}$ \\ 1 Royal College of Music in Stockholm \\ ${ }^{2}$ KTH Royal Institute of Technology \\ gulz@kth.se
}

\begin{abstract}
The primary purpose of this paper is to describe a method to investigate the communication process between musicians performing improvisation in jazz. This method was applied in a first case study. The paper contributes to jazz improvisation theory towards embracing more artistic expressions and choices made in real life musical situations. In jazz, applied improvisation theory usually consists of scale and harmony studies within quantized rhythmic patterns. The ensembles in the study were duos performed by the author at the piano and horn players (trumpet, alto saxophone, clarinet and trombone). Recording sessions involving the ensembles were conducted. The recording was transcribed using software and the produced score together with the audio recording was used when conducting in-depth interviews, to identify the horn player's underlying musical strategies. The strategies were coded according to previous research.
\end{abstract}

Keywords: improvisation, jazz, improvisation strategies, musical interaction, musical communication

\section{Introduction}

Improvising is an activity that raises great interest in many disciplines. What defines a free improvisation? When is prior knowledge required for an improvisation? The ethnomusicologist Bruno Nettl summarizes how the term improvisation has been treated historically in music research [1]. He describes how improvisation for a long time was ignored and how it later on, based on a Western music tradition, was used as an opposite activity to composition. The improvisation was to be considered as the musician's way of putting a personal touch to the music through interpretation. Regardless of how we approach the concept of improvisation, the aim for the definitions are different even if we limit ourselves to improvisation within the music field and exclude all other sorts of improvisation.

This study deals with jazz music where improvisation is very central, and therefore we need a definition of the term jazz improvisation. The British musicologist and guitar player Thomas Williams makes the following definition of improvisation in jazz that is useful in this study: 
"Improvisation in jazz is an extemporaneous activity in which performers navigate complex mental processes to produce musical utterances that aim to be at once novel, spontaneous and interesting and also communicative (both to the wider ensemble and audience), well-structured and familiar." [2]

Within the jazz community, improvisation is based on the ability to contribute from a mutual platform within a mutual language. On top of this mutual language, which is partly described in traditional jazz theory, there are other elements that more refer to personal expressions of each musician.

There are different ways for jazz musicians to practice improvisation, from developing the more traditional form of storytelling [3][4], which is mostly built on a practice-based vocabulary of phrases, into the free jazz language with extended degrees of freedom. Analyzing the horizontal lines as melodies by using tools from melody analysis is one way to acquire some of the basic knowledge in jazz improvisation, and therefore there are many transcriptions of famous jazz musicians' solos available. In addition to books with transcriptions, there are also larger projects such as the Jazzomat project with a very extensive database of solo transcriptions [5]. This kind of analysis fits well with the jazz theory that is usually taught, a theory developed from extended classical music theory with the use of functional harmony.

A theme specifically addressed in this study are the strategies used by musicians when the first barriers in the form of limited instrument skills and insufficient knowledge of basic jazz theory have been overcome. With a starting point in Norgaard's [6] categorization of improvisation strategies, Williams [2] has developed five main categories of strategies on which this study is based:

1. Rhythmic (timing)

2. Pitch (chord scales, melody, harmony)

3. Timbral (i.e. instrument sound, effects)

4. Physical (physical klichs, phrases)

5. Dialogical (interaction)

The purpose of this study was mainly to design and test a methodology to uncover strategies in an unprepared jazz improvisation setting. The results from asking the participants were adapted to the coding system by Williams [2]. We will discuss the advantages and shortcomings of this coding system, with the goal to extend and apply it in an upcoming study with Swedish professional jazz musicians.

\section{Experiment}

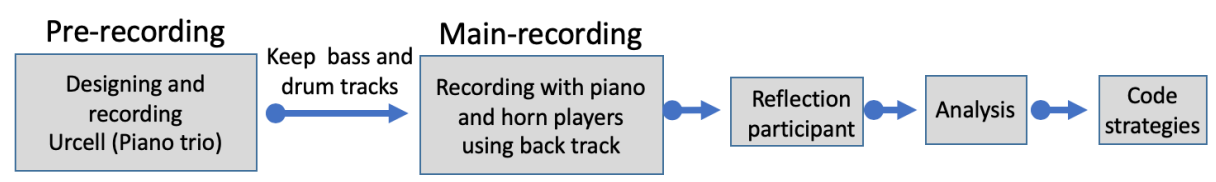

Fig. 1: Method applied in this study. 
Figure 1 illustrates the process that underlies the study presented in this paper, which will be explained in the following parts of this section.

\subsection{Music Material}

In the preparatory stage five different piano trio schematic scores, called Urcells (Fig. 2), were performed and recorded, which later served as the musical platform for the duo improvisations (main-recording). The label Urcell is used through this paper to define the musical core of the experiment. The only instructions available in the score were implicit instructions, based on few chords or scales for the different six parts that lasted about one minute each. The five Urcells were deliberately composed with both easier and more difficult passages according to chord and chord scales. The studio recording with the piano trio was performed in a authentic recording environment by professional musicians. Every part of the Urcell was scheduled to be about one minute, with some variation due to the musical form. After the recording, the audio signals from the double bass were mixed down to a single track and all drums were mixed down to a stereo track, whereas the piano was muted. The six parts of the Urcells were:

URCELL 2 TOTAL 6 MIN

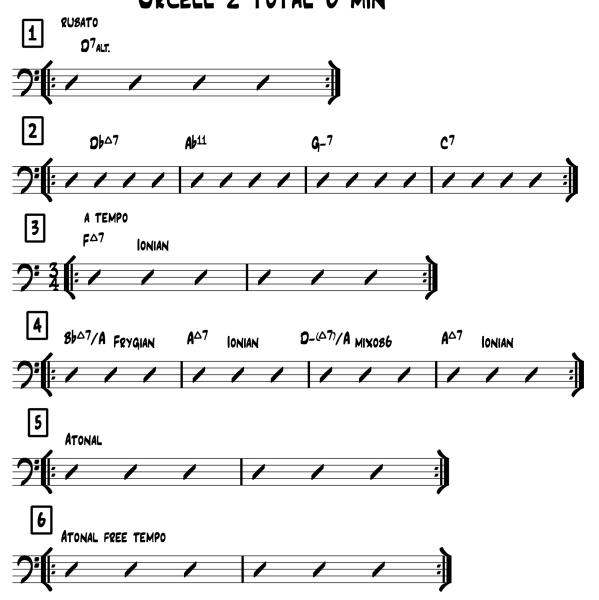

1. Rubato, with one chord scale.

2. Rubato, harmonic movement with four chord scales.

3. A tempo, with one chord scale.

4. A tempo, harmonic movement with four chord scales.

5. A tempo, atonal

6. Rubato, atonal

Fig. 2: Example of the score from one of the Urcells used.

\subsection{Main Recording}

The main recording was performed with no visual contact between the musicians. The core of the music was the six-minute Urcell, based on the prerecorded material described in Section 2.1. The first four minutes of the main recording - before entering the Urcell - a freely improvised part without given conditions was played. This was merely for letting the musicians get into the music gradually. The Urcell together with the free introduction was to be seen as a whole composition-form. It was important, even though the recording was part of a 
research study, to strive for a realistic artistic result. The recording environment resembled the situation within a real record session.

\subsection{Participants}

The participants in the study were four male advanced music students (age 22-26 years) from the jazz department of the Royal College of Music (KMH) in Stockholm, Sweden. The students were selected based on musical skills and their interest to contribute to the research study. All students were horn players and the four instruments used were trumpet, clarinet, alto saxophone and trombone. In addition to these students, the first author played the grand piano to complete the duo in the main recordings. The students faced a basically unprepared musical situation except for information about the aims of the experiment. The participants in the piano trio (pre-recording) were professional jazz musicians.

All participants filled in a consent form and were then informed about the basic idea of the experiment setup. The participants were also informed that a subsequent reflection would be asked for.

\subsection{Equipment and Setup}

The pre-recordings with the piano trio playing the Urcells were made in a studio at KMH. A Steinway grand, double bass and drum set were recorded on multitrack. All instruments were in separate rooms to avoid audio signals leakage. The main recordings of the study were conducted in a studio at the Royal Institute of Technology (KTH), using a Yamaha Disklavier with MIDI Output, two-channel USB sound card M-audio (fast track pro), and an Aston microphone (Spirit) for the horn players. The bass and drum tracks from the pre-recording were used as a back-track for horn and piano player in the main recording. The musician's reflection on the studio material and the analysis were recorded with a Zoom (H2n), while the analysis (score) was presented on a large monitor and the music was replayed in an audio system.

\subsection{Data Analysis}

Recording the piano part in the main recording via midi facilitated an accurate transcription of the piano using built in functions of Logic Pro X. The virtual sound of the grand piano (East-West piano platinum [7]) was found indiscernible from the acoustic sound by the participants. To obtain a simplified notation from the acoustic recordings of the horns, built-in features of Logic Pro X were used. The functions are inside the Flex Pitch module and are mostly used for pitch correction but in this case these functions were used as a transcription/visualization tool. Finally, the interpretation of the pitches was transformed into a MIDI-track and the score was presented.

This analysis was done immediately after the main recordings, and was accompanied by some transcription errors. Most of them were possible to adjust 
in the flex pitch window by listening and transcribing traditionally by ear, and the obtained score was found to be sufficient as a starting point for reflection on the musicians strategies.

\subsection{Reflection (Musician)}

The reflection was performed in front of a monitor, and the principal focus was on the horn player's score. The score, along with the audio from the recording and with the ability to stop and rewind, provided sufficient information. Only limited guidance was provided for the reflection, in order not to influence the participant's reflection. Each reflection lasted for about 40 minutes. As a complement to the reflection, participants filled in a questionnaire with general questions regarding musical experience and background.

\section{Results}

The main results of the study concern method development. The method proposed here can, of course, be refined and further developed which is on the agenda for the continued research. Overall, the experimental situation was well adapted to describe some of the improvisation strategies in jazz, and specifically in treating how the improvisation output changes direction when conditions change. In this study the conditions differed due to the design of the Urcell.

With this study, the work also continues to categorize strategies within jazz improvisation. As role models, Martin Norgaard's [6] and Thomas Williams' [2] previous work are used to identify possible strategies and to group them. The main categories, (Rhythmic, Pitch, Dialogical, Timbral and Physical) are from the research of Williams. The students have been able to identify personal strategies by playing and then reflecting on their musical choices but they were not presented to the main categories by Williams in advance. Below examples ${ }^{3}$ are provided of different strategies that have emerged during the study through the reflections by the participants.

a) Half step: the participant recognized that the note sounded out of scale and changed a half step up. In this case, the student discussed whether he actually perceived his note as the minor third, perceived a half note under the major third or just changed note because it sounded wrong, see Figure 3a.

b) Chromatic: the participant played chromatic melodic movements to postpone the resolution in the chord scale, see Figure $3 \mathrm{~b}$.

c) Pentatonic: the participant played a pentatonic scale. They are commonly used within the chord scale as well as outside the chord scale. This type of pentatonic scales belongs to what jazz musicians practice, attributing this strategy to the category Physical [2], see Figure 3c.

d) Tied notes: The participant kept to the same note when the chord changed and one strategy was to rapidly identify the function of the note. In this case

\footnotetext{
${ }^{3}$ Examples available at https://bit.ly/2YiNw9o
} 
the participant immediately felt that the note (eb) change from being the $b 9$ in the $\mathrm{D}$ altered scale to the 9 th in the new chord (Dbmaj7), see Figure 3d.

e) Stick to few notes: The participant decided to play few notes that belong to all chord scales in the example. In this example it is a trombone player. Fig. 3e. f) Scale-wise: The participant quickly identified the scale and could in a more secure way play pre-produced patterns or new ones, see Figure 3f.

g) Copy notes: In this case the participant copied the note a from the piano and repeated it, see Figure $3 \mathrm{~g}$.

All strategies that emerged from the reflections were grouped according to Williams [2] as follows:

- Rhythmic: few notes

- Pitch: half step, scale-wise, chromatic, tied notes

- Dialogical: copy notes

- Timbral: idiomatic techniques

- Physical: phrases, pentatonic

There are advantages to grouping the strategies into main categories, and they were mainly applicable in this study. All categories are described by their names besides the category Physical, which is also a category developed partly from a guitar player's perspective. There is thus reason to review the categories and also to decide how the best representation of an individual strategy that falls under different categories would be.

\section{Discussion}

The central theme of this pilot study has been methodological development since there are few previous studies to be based on. In an upcoming study with Swedish professional jazz musicians this method will be applied on a larger scale. In this kind of experiment it will always be essential to create a positive experimental situation, especially as this design of recordings can be experienced as demanding both in an artistic and a technical sense. Therefore, the introduction is particularly important, including soundcheck and rehearsal of some tunes. The surrounding environment can affect participants motivation for the experiment. It is often discussed among musicians how an optimal recording environment would look and work and several of the thoughts were directly transferable to this study. The students who participated in the pilot study were predominantly positive to the study. Above all, it was noticed how the method developed, in which the participants' performance was carefully analyzed and discussed, provided great opportunities for further development of the participants' musical development. The method can thus advantageously probably also be used as a teaching tool.

During the composition/construction process of the Urcell, it was essential that the whole piece obtains a functional musical form. Also, it should not be protracted to ensure that the concentration of the musician did not disappear. At the same time, for the data collection of the experiment, enough time must be 


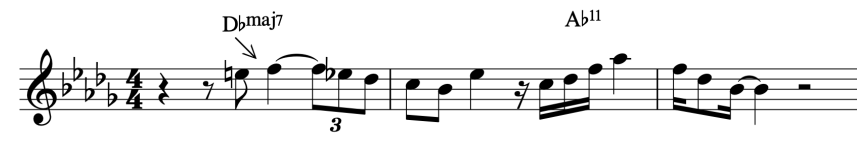

(a) Changing notes by a half step to arrive in the chord scale. (Clarinet score, non transposed)

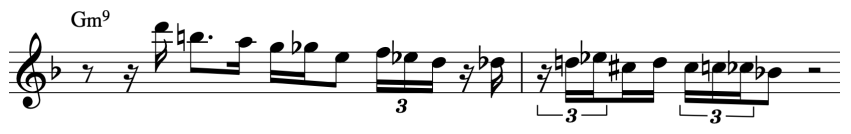

(b) Using chromatism to postpone the resolution. (Clarinet score, non transposed)

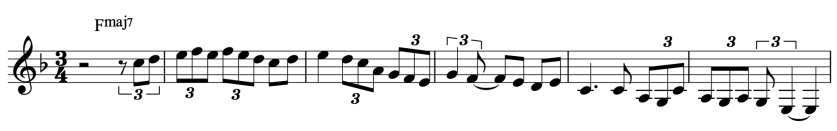

(c) Using pentatonic phrases to play inside or outside the chord scale. (Clarinet score, non transposed)

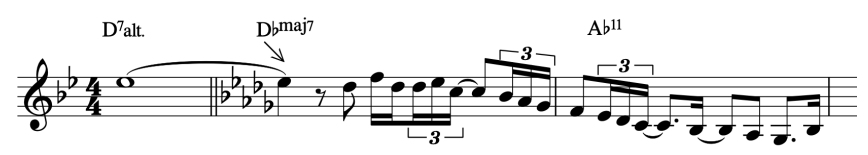

(d) How to understand the new function of the withheld note when the chord scale changes. (Clarinet score, non transposed)

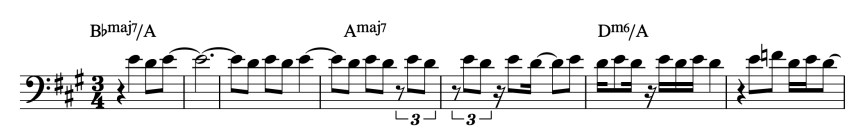

(e) Example of sticking to few notes that are connecting chord scales and instead to use rhythmic variation. (Trombone score)

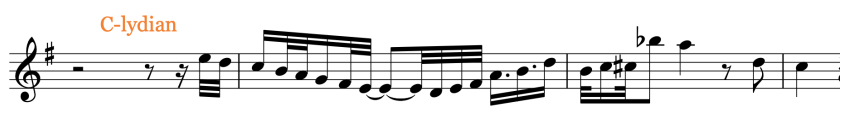

(f) Example of identifying the chord scale and to stay within it. (Trumpet score, non transposed)

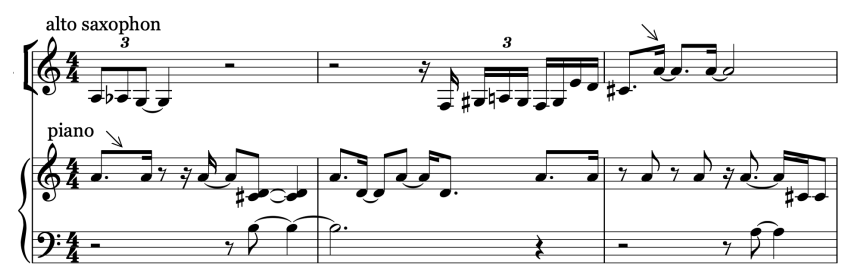

(g) Note copying via dialogical interaction (alto saxophone and piano scores, non transposed)

Fig. 3: Examples of applied strategies. 
available for each part. The structure with an Urcell consisting of six one-minute parts was found to be a reasonable length during the pilot study. The elements that are based on simple scales have in most cases been experienced as easy to decipher but have also provided an opportunity for a looser musical language where the musician takes off from a safe musical environment. The playing of parts that are moving faster from one chord scale to another create, with greater uncertainty, a more pending outcome. The accuracy of the analysis was high in this study compared to just recording and listening and the discussions were concrete and directly linked to the practice. One of the most interesting insights from the reflections and the survey is the impact that good ear training has on the participants self-confidence, which in turn leads to a larger palette of strategies.

\section{Conclusion}

To improvise in jazz is complex. This study shows the possibility to use a structured analysis of a musician's improvisation strategy through a method that provides a flexible framework but also retains space for the musician's freedom to create. The result offers a palette of strategies that move in several areas from music theory to individual choices. The main categories developed by Williams [2] seem well suited to this study, but will be further improved when conducting an extended study with more experienced jazz musicians where the frequency of occurrence of the various strategies will be investigated. The musical core of the recording, the Urcell, will be instrumental in these future experiments to bring to light the dependence of various strategies on how complex the parts are regarding rhythm and harmony.

\section{References}

1. B. Nettl, "Contemplating the Concept of Improvisation and Its History in Scholarship," Music Theory Online, vol. 19, no. 2, pp. 4-7, 2018.

2. T. Williams, M. Mermikides, and J. Barham, "Strategy in Contemporary Jazz Improvisation: Theory and Practice," Ph.D. dissertation, University of Surrey, 2017.

3. P. F. Berliner, Thinking in jazz: the infinite art of improvisation. University of Chicago Press, 1994.

4. S. Bjerstedt, "Storytelling in Jazz Improvisation: Implications of a Rich Intermedial Metaphor," Ph.D. dissertation, University of Lund, 2014.

5. M. Pfleiderer, K. Frieler, J. Abeßer, W.-G. Zaddach, and B. Burkhart, Inside the Jazzomat: New Perspectives for Jazz Research. Schott Campus, 2017.

6. M. Norgaard, "Descriptions of Improvisational Thinking by Artist-Level Jazz Musicians," Ph.D. dissertation, University of Texas, 2008.

7. "http://www.soundsonline.com/pianos ." EASTWEST/QUANTUM LEAP. 